\title{
BMJ Open Radiation-related anxiety among public health nurses in the Fukushima Prefecture after the accident at the Fukushima Daiichi Nuclear Power Station: a cross-sectional study
}

Koji Yoshida, ${ }^{1,2}$ Makiko Orita, ${ }^{3}$ Aya Goto, ${ }^{4}$ Atsushi Kumagai, ${ }^{2}$ Kiyotaka Yasui, ${ }^{2}$ Akira Ohtsuru, ${ }^{5}$ Naomi Hayashida, ${ }^{6}$ Takashi Kudo, ${ }^{7}$ Shunichi Yamashita, ${ }^{8}$ Noboru Takamura ${ }^{3}$

To cite: Yoshida K, Orita M, Goto $\mathrm{A}$, et al. Radiationrelated anxiety among public health nurses in the Fukushima Prefecture after the accident at the Fukushima Daiichi Nuclear Power Station: a cross-sectional study. BMJ Open 2016;6: e013564. doi:10.1136/ bmjopen-2016-013564

- Prepublication history for this paper is available online. To view these files please visit the journal online (http://dx.doi.org/10.1136/ bmjopen-2016-013564).

Received 21 July 2016 Revised 29 September 2016 Accepted 3 October 2016

CrossMark

For numbered affiliations see end of article.

Correspondence to

Koji Yoshida;

koujiy@nagasaki-u.ac.jp

\section{ABSTRACT}

Objective: In Japan, public health nurses (PHNs) play important roles in managing the health of local residents, especially after a disaster. In this study, we assessed radiation anxiety and the stress processing capacity of PHNs in the Fukushima Prefecture in Japan, after the accident at the Fukushima Daiichi Nuclear Power Station (FDNPS).

Methods: We conducted a questionnaire survey among the PHNs $(n=430)$ in July of 2015 via postal mail. The questions included demographic factors (sex, age and employment position), knowledge about radiation, degree of anxiety about radiation at the time of the FDNPS accident (and at present), by asking them to answer questions about radiation and the Sense of Coherence-13 (SOC-13). We classified the low and high levels of anxiety by asking them to answer questions about radiation, and compared the anxiety-negative (-) group with the anxiety-positive $(+)$ group.

Results: Of the PHNs, 269 (62.6\%) were classified in the anxiety (-) group and $161(37.4 \%)$ were in the anxiety (+) group. When the multivariate logistic regression analysis was conducted, the PHNs at the time of the accident (OR: 2.37, $p=0.007$ ), current general anxieties about radiation (OR: $3.56, p<0.001$ ), current possession of materials to obtain knowledge about radiation (OR: 2.11, $p=0.006$ ) and knowledge of the childhood thyroid cancer increase after the Chernobyl accident (OR: 1.69, $\mathrm{p}=0.035$ ) were significantly associated with anxiety after the FDNPS accident. The mean SOC-13 was $43.0 \pm 7.7$, with no significant difference between the anxiety $(-)$ group and anxiety $(+)$ group ( $p=0.47)$.

Conclusions: Our study suggested that anxiety about radiation was associated with materials and knowledge about radiation in the PHNs in the Fukushima Prefecture 4 years after the FDNPS accident. It is important for PHNs to obtain knowledge and teaching materials about radiation, and radiation education programmes for PHNs must be established in areas that have nuclear facilities.

\section{Strengths and limitations of this study}

We could assess radiation anxiety and the stress processing capacity of public health nurses (PHNs) in the Fukushima Prefecture in Japan, after the accident at the Fukushima Daiichi Nuclear Power Station (FDNPS).

- We believe that this study regarding the PHNs' situation in the Fukushima Prefecture 4 years after the FDNPS disaster will be very important in the provision of future support.

- We could not obtain sufficient information on the anxiety-related factors, such as detailed consultation contents and other information.

- We were not able to gather sufficient information on stress management factors, such as family issues and marital status.

\section{INTRODUCTION}

On 11 March 2011, the Great East Japan Earthquake struck the east coast of Japan. This large earthquake and tsunami caused immense damage, including that to the Fukushima Daiichi Nuclear Power Station (FDNPS). ${ }^{1-4}$ After the accident at the FDNPS, the Fukushima prefectural government immediately issued instructions for the evacuation of those areas within a $20 \mathrm{~km}$ radius of the FDNPS, and they also instructed sheltering in the areas between 20 and $30 \mathrm{~km}$ from the FDNPS. Beyond the $30 \mathrm{~km}$ radius, additional areas were designated 'deliberate evacuation areas' if there was concern that the cumulative doses of radiation might reach $20 \mathrm{mSv}$ per year in those areas. ${ }^{2}$ Despite the low estimated and measured external and internal exposure doses just after the accident, many residents 
of the Fukushima Prefecture evacuated inside or outside the prefecture. ${ }^{5-8}$

In the report by the WHO on the health impacts 20 years after the Chernobyl accident, mental health was described as the most serious public health problem resulting from that nuclear accident. $^{9-11}$ Based on the lessons learnt from the Chernobyl accident, the Fukushima Health Management Survey (FHMS) was initiated to assess the health impacts, including mental health, of the residents by the Fukushima prefectural government and the Fukushima Medical University. ${ }^{12} 13$ According to the results of this survey, the residents of the Fukushima Prefecture were exposed to a higher risk of physical problems, such as diabetes and obesity, as well as mental problems (including the risk perception of the health effects of radiation).$^{14} 15$

In Japan, public health nurses (PHNs) hold a national license, and many PHNs work for prefectural and municipal bodies, enabling them to provide community health services such as health guidance, home visits and health education to local residents. In other words, they play important roles in managing the health of local residents, including the time after this disaster. While they were themselves victims of the radiation disaster, they had to respond to the residents' anxieties about radiation exposure, despite their lack of professional knowledge on this topic.

In this study, we conducted a survey to clarify the radiation anxiety and stress processing capacity of the PHNs in the Fukushima Prefecture, after the nuclear accident at the FDNPS.

\section{MATERIALS AND METHODS}

\section{Study population and data collection}

We conducted a questionnaire survey among the PHNs in the Fukushima Prefecture located in Northeastern Japan, which was severely affected by the earthquake, tsunami and FDNPS accident following the Great East Japan Earthquake in 2011. We initially distributed questionnaires to $509 \mathrm{PHNs}$, and we obtained responses from 458 PHNs (90.0\%), after excluding 28 PHNs with insufficient responses. The survey was conducted in July of 2015 via postal mail, and contained questions about the demographic factors (sex, age, activity area and employment position) and knowledge of the PHNs about radiation before and after the accident at the FDNPS, as well as their mental health status. In addition, we examined their degree of anxiety about radiation at the time of the FDNPS accident, and at present, by asking them to answer questions about radiation at present. The degree of anxiety was rated on a 10-point Likert scale ranging from no anxiety to having a lot of anxiety; we defined $1-5$ as 'anxiety (-)' and $6-10$ as 'anxiety $(+)$.'

To measure the PHNs' stress management capability, we used the Japanese version of the Sense of Coherence-13 (SOC-13). The SOC-13 consists of three dimensions (comprehensibility, manageability and meaningfulness) that are equally weighted to create an overall (total) score. Each question was rated on a five-point Likert scale from 1 to five, with a higher score representing a stronger sense of coherence (range:13-65). ${ }^{16}$

\section{Statistical analysis}

We classified the low and high levels of anxiety by asking them to answer questions about radiation, and compared the anxiety (-) group and anxiety $(+)$ group by using the $\chi^{2}$ test and t-test as univariate analyses. A multiple logistic regression analysis was performed to assess the effects of each variable on the anxiety level adjusted for confounding variables. In this study, the dependent variable was 'the anxiety (+) by asking them to answer questions about radiation,' the exposure variables were 'Manager in the workplace,' 'Public health nurse at the time of the accident,' 'Current degree of anxiety about radiation,' 'Difficulty answering radiation questions in the past,' 'Currently have materials to obtain knowledge about radiation' and 'Knowledge about childhood thyroid cancer increase after the Chernobyl accident', and the confounding variable was 'age'. ORs and their $95 \%$ CI were also calculated. A $p$ value of $<0.05$ was considered to be significant, and the statistical analysis was performed using SPSS Statistics V.22.0 (IBM Japan, Tokyo, Japan).

\section{RESULTS}

A total of 458 PHNs responded to the survey, and 430 of those PHNs (93.9\%) completed all of the questions. The number of women was $416(96.7 \%)$, and 153 $(35.6 \%)$ were aged 50 years or older. The number of PHNs with $<10$ years of working experience was 124 $(22.8 \%)$, and $306(71.2 \%)$ had 10 years or more. There were 119 participants $(27.7 \%)$ in managerial positions. At the time of the accident, $330(76.8 \%)$ worked as PHNs and $62(14.4 \%)$ were still in training. The number of those in Hamadori, which became the evacuation area of the FDNPS accident, was $83(19.3 \%)$ (table 1).

Of the PHNs, 269 were classified in the anxiety (-) group and 161 were in the anxiety (+) group (table 2 ). A significantly higher ratio of PHNs younger than 40 years of age was observed in the anxiety $(+)$ group ( $p<0.001$, table 2). Likewise, higher ratios of PHNs with $<10$ years of working experience, staff positions and nursing licenses were observed in the anxiety $(+)$ group ( $p<0.001$, respectively, table 2$)$. On the other hand, no significant differences were observed between the two groups in the activity area, education curriculum and seminars before or after the accident $(p=0.62$, $\mathrm{p}=0.16, \mathrm{p}=0.60$ and $\mathrm{p}=0.13$, respectively, table 2). In addition, there was no significant difference in the mean points in the SOC-13 observed between the two groups $(\mathrm{p}=0.47$, table 2$)$.

In the anxiety $(+)$ group, the ratio of those having current anxiety about radiation was significantly higher 
than that in the anxiety $(-)$ group $(\mathrm{p}<0.001$, table 3$)$. On the other hand, in the anxiety (-) group, the ratios with difficulty answering the questions about radiation, currently having the materials to obtain knowledge about radiation and having knowledge about childhood thyroid cancer increases after the Chernobyl accident were significantly higher than in the anxiety $(+)$ group $(\mathrm{p}<0.05$, $\mathrm{p}<0.01$ and $\mathrm{p}<0.05$, respectively, table 3 ). However, there

\begin{tabular}{lc}
\hline Table $1 \quad$ Basic characteristics of the study participants \\
\hline Variable & Number (\%) \\
\hline Gender & \\
Women & $416(96.7)$ \\
Men & $14(3.3)$ \\
Age (years old) & \\
$20-29$ & $92(21.4)$ \\
$30-39$ & $72(16.7)$ \\
$40-49$ & $113(26.3)$ \\
$\geq 50$ & $153(35.6)$ \\
Tenure as a public health nurse (years) & \\
$<10$ & $124(28.8)$ \\
$\geq 10$ & $306(71.2)$ \\
Nursing experience in a hospital & $149(34.7)$ \\
Yes & $281(65.3)$ \\
No & \\
Activity area & $83(19.3)$ \\
Hamadori & $347(80.7)$ \\
Other area (Nakadori, Aizu, etc) & \\
Position in the workplace & $119(27.7)$ \\
Manager (director, chief) & $311(72.3)$ \\
Staff & \\
Occupation at the time of the accident & $330(76.8)$ \\
Public health nurse & $62(14.4)$ \\
Other occupations (mostly nurses) & \\
Students & \\
\hline
\end{tabular}

were no significant changes between the two groups in the anxiety about radiation at the time of the accident and the recognition of health effects (such as late effects and genetic effects) due to radiation exposure $(p=0.68$, $\mathrm{p}=0.79$ and $\mathrm{p}=0.20$, respectively, table 3 ).

When the logistic regression analysis was conducted, following the adjustment for confounding factors, being a PHN at the time of the accident (OR: 2.37, p<0.01), current general anxieties about radiation (OR: 3.56, $\mathrm{p}<0.001$ ), currently having the materials to obtain knowledge about radiation (OR: 2.11, $\mathrm{p}<0.01$ ) and having knowledge about childhood thyroid cancer increases after the Chernobyl accident (OR: 1.69, $\mathrm{p}=0.04$ ) were all significantly associated with anxiety after the FDNPS accident (table 4).

\section{DISCUSSION}

This study was conducted 4 years after the FDNPS disaster to provide educational support for PHNs who receive many consultations from residents. In univariate analysis, younger and inexperienced PHNs had higher anxiety with regard to communicating with residents about radiation. When adjusting for other variables, those PHNs who were students at the time of the accident had higher anxiety when communicating with residents about radiation. Our results suggested that experience as a professional during the FDNPS accident is important. Although many of the PHNs had knowledge about the Chernobyl accident, they could not properly communicate the health effects of radiation with the residents, which caused anxiety in the residents after the accident at the FDNPS. In addition, our results showed that having the materials to obtain knowledge about radiation was independently associated with anxiety about the FDNPS accident.

Table 2 Participant's demographic factors, educational history and mental health via anxiety with regard to questions about radiation after the FDNPS accident

\begin{tabular}{|c|c|c|c|c|}
\hline Variable & Unit & $\begin{array}{l}\text { Anxiety }(-) \\
(n=269)(\%)\end{array}$ & $\begin{array}{l}\text { Anxiety }(+) \\
(n=161)(\%)\end{array}$ & $\begin{array}{l}\mathbf{p} \\
\text { Values }\end{array}$ \\
\hline Gender & Women/men & $262(97.4) / 7(2.6)$ & $154(95.7) / 7(4.3)$ & 0.32 \\
\hline Age & $\begin{array}{l}<40 \text { years old } / \geq 40 \text { years } \\
\text { old }\end{array}$ & $77(28.6) / 192(71.4)$ & $87(54.0) / 74(46.0)$ & $<0.001$ \\
\hline Working experience as a public health nurse & $<10$ years $/ \geq 10$ years & $53(19.7) / 216(80.3)$ & $71(44.1) / 90(55.9)$ & $<0.001$ \\
\hline Activity area & Hamadori/other area & $54(20.1) / 215(79.9)$ & $29(18.0) / 132(72.0)$ & 0.62 \\
\hline Position in the workplace & Manager/staff & $88(32.7) / 181(67.3)$ & $31(19.3) / 130(80.7)$ & 0.003 \\
\hline Occupation at the time of the accident & $\begin{array}{l}\text { PHNs/others (nurses, } \\
\text { students) }\end{array}$ & $230(85.5) / 39(14.5)$ & $100(62.1) / 61(37.9)$ & $<0.001$ \\
\hline $\begin{array}{l}\text { Did you have children aged } \leq 15 \text { years at the } \\
\text { time of the accident? }\end{array}$ & Yes & $110(40.9)$ & $59(36.6)$ & 0.42 \\
\hline Education history in curriculum & Yes & $114(42.4)$ & $80(49.7)$ & 0.16 \\
\hline Education history in seminar before the accident & Yes & $25(9.3)$ & $12(7.5)$ & 0.60 \\
\hline Education history in seminar after the accident & Yes & $247(91.8)$ & $140(87.0)$ & 0.13 \\
\hline Frequency of participation in seminars & Once/plural & $47(19.0) / 200(81.0)$ & $42(29.6) / 98(70.4)$ & 0.02 \\
\hline SOC-13 total points & Mean & 44.0 & 41.4 & 0.47 \\
\hline
\end{tabular}


Table 3 Participants' anxiety, recognition and knowledge about radiation via anxiety with regard to answering the questions about radiation after the FDNPS accident

\begin{tabular}{|c|c|c|c|c|}
\hline Question & Unit & $\begin{array}{l}\text { Anxiety }(-) \\
(n=269)(\%)\end{array}$ & $\begin{array}{l}\text { Anxiety }(+) \\
(n=161)(\%)\end{array}$ & $\begin{array}{l}p \\
\text { Values }\end{array}$ \\
\hline $\begin{array}{l}\text { Degree of anxiety about radiation at the time of } \\
\text { the FDNPS accident }\end{array}$ & $\begin{array}{l}\text { Anxiety } \\
(-) / \text { anxiety (+) }\end{array}$ & $99(36.8) / 170(63.2)$ & $56(34.8) / 105(65.2)$ & 0.68 \\
\hline Degree of anxiety about radiation currently & $\begin{array}{l}\text { Anxiety } \\
(-) / \text { anxiety }(+)\end{array}$ & $251(93.3) / 18(6.7)$ & $130(80.7) / 31(19.3)$ & $<0.001$ \\
\hline $\begin{array}{l}\text { Do you think that delayed effects such as } \\
\text { malignancies occur due to radiation exposure } \\
\text { following the Fukushima accident? }\end{array}$ & Yes & $37(13.8)$ & $33(20.5)$ & 0.79 \\
\hline $\begin{array}{l}\text { Do you think that genetic effects in offspring occur } \\
\text { due to radiation exposure following the } \\
\text { Fukushima accident? }\end{array}$ & Yes & $33(12.3)$ & $27(16.8)$ & 0.20 \\
\hline $\begin{array}{l}\text { Did you have a difficult time answering the } \\
\text { questions about radiation? }\end{array}$ & Yes & $216(80.3)$ & $115(71.4)$ & 0.04 \\
\hline $\begin{array}{l}\text { Did you have the materials to obtain knowledge } \\
\text { about radiation at the time of the accident? }\end{array}$ & Yes & $87(32.3)$ & $40(24.8)$ & 0.10 \\
\hline $\begin{array}{l}\text { Do you currently have the materials to obtain } \\
\text { knowledge about radiation? }\end{array}$ & Yes & $233(86.6)$ & $118(73.3)$ & 0.01 \\
\hline $\begin{array}{l}\text { Did you know about the three principles of } \\
\text { radiation protection? }\end{array}$ & Yes & $64(23.8)$ & $42(26.1)$ & 0.64 \\
\hline $\begin{array}{l}\text { Did you know about the annual dose limit for the } \\
\text { general public? }\end{array}$ & Yes & $20(12.4)$ & $11(6.8)$ & 0.99 \\
\hline $\begin{array}{l}\text { Did you know about the half-life of radioactive } \\
\text { substances? }\end{array}$ & Yes & $129(48.0)$ & $77(47.8)$ & 0.99 \\
\hline $\begin{array}{l}\text { Did you know about childhood thyroid cancer } \\
\text { increases after the Chernobyl accident? }\end{array}$ & Yes & $213(79.2)$ & $109(67.7)$ & 0.01 \\
\hline
\end{tabular}

Table 4 ORs and $95 \% \mathrm{Cls}$ of the study variables for anxiety (+) by asking participants to answer questions about radiation, as assessed by the logistic regression analysis

\begin{tabular}{|c|c|c|c|c|}
\hline Variable & Unit & OR & $95 \% \mathrm{Cl}$ & p Value \\
\hline \multicolumn{5}{|l|}{ Adjusted } \\
\hline Age & $\geq 40$ years old & 0.64 & 0.36 to 1.15 & 0.13 \\
\hline Manager in the workplace & No & 1.14 & 0.65 to 2.00 & 0.66 \\
\hline Public health nurse at the time of the accident & No & 2.37 & 1.27 to 4.42 & 0.007 \\
\hline Current degree of anxiety about radiation & anxiety (+) & 3.56 & 1.82 to 6.96 & $<0.001$ \\
\hline Difficulty answering radiation questions in the past & No & 1.27 & 0.76 to 2.12 & 0.37 \\
\hline $\begin{array}{l}\text { Currently have materials to obtain knowledge about } \\
\text { radiation }\end{array}$ & No & 2.11 & 1.25 to 3.60 & 0.006 \\
\hline $\begin{array}{l}\text { Knowledge about childhood thyroid cancer increase } \\
\text { after the Chernobyl accident } \\
\text { Unadjusted }\end{array}$ & No & 1.69 & 1.04 to 2.75 & 0.04 \\
\hline Age & $\geq 40$ years old & 0.34 & 0.23 to 0.51 & $<0.001$ \\
\hline Manager in the workplace & No & 2.04 & 1.28 to 3.25 & 0.003 \\
\hline Public health nurse at the time of the accident & No & 3.60 & 2.26 to 5.73 & $<0.001$ \\
\hline Current degree of anxiety about radiation & anxiety (+) & 3.33 & 1.79 to 6.17 & $<0.001$ \\
\hline Difficulty answering radiation questions in the past & No & 1.63 & 1.03 to 2.57 & 0.04 \\
\hline $\begin{array}{l}\text { Currently have materials to obtain knowledge about } \\
\text { radiation }\end{array}$ & No & 2.36 & 1.44 to 3.87 & $<0.001$ \\
\hline $\begin{array}{l}\text { Knowledge about childhood thyroid cancer increase } \\
\text { after the Chernobyl accident }\end{array}$ & No & 1.82 & 1.17 to 2.82 & 0.008 \\
\hline
\end{tabular}

These results suggest that continuous effort is necessary to provide education and materials among the PHNs in the Fukushima Prefecture for them to gain knowledge about radiation, including the health effects caused by radiation exposure. ${ }^{17}$ Some education initiatives have been undertaken in the prefecture after the nuclear accident, which includes Fukushima Medical University's disaster education for undergraduates and 
health literacy training for PHNs for field practitioners. ${ }^{18} 19$ Appropriate and sustainable allocation of financial and human resources is needed to continue and expand such activities.

The SOC was employed to estimate the stress management capability of the PHNs in this study. There was no significant difference in the mean points in the SOC observed between the anxiety (-) group and anxiety $(+)$ group. This result, as well as results from other studies, may suggest that lifestyle factors are related. ${ }^{20}$ On the other hand, Eriksson $e t a l^{21}$ showed that individuals with high scores in the SOC are better able to cope with chronic stress than those with low scores. In other studies, the average points of the nurses at two Japanese hospitals were $38.5 \pm 6.4$ and $39.3 \pm 6.3$, respectively, ${ }^{22}{ }^{23}$ and the average score of mothers of children with intellectual disabilities in Japan was $40.0 \pm 8.0 .^{24}$ In this study, the average score $(43.0 \pm 7.7)$ was higher than those in other studies, and it was substantially higher when compared to those of nurses. We believe that expertise as a public health nurse is one of the factors that increases the SOC. Accordingly, in order to maintain high scores in the SOC, there is a need for planning of stress management capacity improvement for the PHNs in Fukushima Prefecture.

The correspondence of the disaster affected the stress management capability, and might cause a worsening of chronic stress. According to the FHMS, which includes monitoring the mental health and daily lives of Fukushima residents and providing proper care for them, the mental health status of the residents in the Fukushima Prefecture was very poor. ${ }^{13}$ Thus, the mental health of the residents was greatly affected by the disaster and a similar impact could be expected from the PHNs who work in the Fukushima Prefecture. Therefore, mental support is important for the PHNs, as well as for the residents of the Fukushima Prefecture.

The present study has several limitations. First, we could not obtain sufficient information on the anxiety-related factors, such as detailed consultation contents and other information. Second, we were not able to gather sufficient information on stress management factors, such as family issues and marital status. Third, this study might have caused a recall bias on the study participants. Finally, since this study targeted PHNs only in Fukushima, Japan, there might be a problem about generalisability. However, we believe that this study regarding the PHNs' situation in the Fukushima Prefecture 4 years after the FDNPS disaster will be very important in the provision of future support.

In conclusion, we conducted a survey of the radiation anxiety and stress processing capacity of PHNs in the Fukushima Prefecture 4 years after the nuclear accident at the FDNPS, and determined that it is important for PHNs to obtain knowledge and teaching materials about radiation. In order to develop workers' capabilities that can correspond to the timing of radiation disasters in the future, radiation education programmes for PHNs and nursing students must be established in areas that have nuclear power stations and other nuclear facilities.

\section{Author affiliations}

${ }^{1}$ Department of Health Sciences, Nagasaki University Graduate School of Biomedical Sciences, Nagasaki, Japan

${ }^{2}$ Education Center for Disaster Medicine, Fukushima Medical University, Fukushima, Japan

${ }^{3}$ Department of Global Health, Medicine and Welfare, Atomic Bomb Disease Institute, Nagasaki University, Nagasaki, Japan

${ }^{4}$ Center for Integrated Science and Humanities, Fukushima Medical University, Fukushima, Japan

${ }^{5}$ Department of Radiation Health Management, Fukushima Medical University School of Medicine, Fukushima, Japan

${ }^{6}$ Division of Promotion of Collaborative Research on Radiation and Environment Health Effects, Atomic Bomb Disease Institute, Nagasaki University, Nagasaki, Japan

${ }^{7}$ Department of Radioisotope Medicine, Atomic Bomb Disease Institute, Nagasaki University, Nagasaki, Japan

${ }^{8}$ Department of Radiation Medical Sciences, Atomic Bomb Disease Institute, Nagasaki University, Nagasaki, Japan

Contributors KY conceived and designed the experiments, analysed the data, wrote the paper and prepared the Tables. MO, AO, AG, AK and KY contributed materials and reviewed drafts of the paper. NH, TK and SY designed the experiments and reviewed drafts of the paper. NT conceived and designed the experiments, wrote the paper and reviewed drafts of the paper.

Funding This study was partly supported by the Japan Society for Promotion of Science.

Competing interests None declared.

Ethics approval The ethics committee of the Fukushima Medical University (number 2251), and conducted in accordance with the guidelines specified in the Declaration of Helsinki.

Provenance and peer review Not commissioned; externally peer reviewed.

Data sharing statement No additional data are available.

Open Access This is an Open Access article distributed in accordance with the Creative Commons Attribution Non Commercial (CC BY-NC 4.0) license, which permits others to distribute, remix, adapt, build upon this work noncommercially, and license their derivative works on different terms, provided the original work is properly cited and the use is non-commercial. See: http:// creativecommons.org/licenses/by-nc/4.0/

\section{REFERENCES}

1. United Nations Scientific Committee on the Effects of Atomic Radiation. UNSCEAR 2013 Report Volume I Report to the general assembly scientific annex $A$ : levels and effects of radiation exposure due to the nuclear accident after the 2011 Great east-Japan earthquake and tsunami. http://www.unscear.org/docs/reports/2013/ 13-85418 Report 2013 Annex A.pdf (accessed 16 Jul 2016).

2. International Atomic Energy Agency. The Fukushima Daiichi accident technical volume 4. Radiological consequences. Vienna: International Atomic Energy Agency (IAEA), 2015:1-250.

3. Nuclear Emergency Response Headquarters of Japanese Government. Report of Japanese government to the IAEA ministerial conference on nuclear safety. The Accident at TEPCO's Fukushima nuclear power stations. http://japan.kantei.go.jp/kan/topics/201106/ iaea_houkokusho_e.html (accessed 16 Jul 2016).

4. Nuclear Emergency Response Headquarters of Japanese Government. Additional report of the Japanese government to the IAEA-The Accident at TEPCO's Fukushima nuclear power stations (Second Report). https://www.iaea.org/newscenter/focus/fukushima/ additional-japan-report (accessed 16 Jul 2016).

5. Nagataki S, Takamura N, Kamiya K, et al. Measurements of individual radiation doses in residents living around the Fukushima Nuclear Power Plant. Rad Res 2013;180:439-47.

6. Nagataki S, Takamura N. A review of the Fukushima nuclear reactor accident: radiation effects on the thyroid and strategies for prevention. Curr Opin Endocrinol Diabetes Obes 2014;21:384-93. 
7. Ishikawa T, Yasumura S, Ozasa K, et al. The Fukushima Health Management Survey: estimation of external doses to residents in Fukushima Prefecture. Sci Rep 2015;5:12712.

8. Yoshida K, Hashiguchi K, Taira Y, et al. Importance of personal dose equivalent evaluation in Fukushima in overcoming social panic. Radiat Prot Dosimetry 2012;151:144-6.

9. WHO (World Health Organization). Health Effects of the Chernoby Accident and Special Healthcare Programmes. 2005. http://www. who.int/ionizing_radiation/a_e/chernobyl/-EGH\%20Master\%20file\% 202005.08.24.pdf (accessed 16 Jul 2016).

10. WHO (World Health Organization). Chernobyl: the true scale of the accident; 20 Years Later a UN Report Provides Definitive Answers and Ways to Repair Lives. 2005. http://www.who.int/mediacentre/ news/releases/2005/pr38/en/ (accessed 16 Jul 2016).

11. WHO (World Health Organization). Health effects of the Chernobyl accident and special healthcare programmes. Geneva: WHO, 2006. http://www.who.int/ionizing_radiation/chernobyl/who_chernobyl_ report 2006.pdf\#search $=\% 2715 .+\mathrm{WHO}+\% 28$ World + Health +Organization\%29.+Health+effects+of+the+Chernobyl+Accident +and+Special+Health+Car\%27.pdf (accessed 16 Jul 2016).

12. Yasumura $\mathrm{S}$, Hosoya $\mathrm{M}$, Yamashita $\mathrm{S}$, et al. Study protocol for the Fukushima health management survey. J Epidemiol 2012;22:375-83.

13. Yabe $H$, Suzuki $Y$, Mashiko $H$, et al. Psychological distress after the Great East Japan Earthquake and Fukushima Daiichi Nuclear Power Plant accident: results of a mental health and lifestyle survey through the Fukushima Health Management Survey in FY2011 and FY2012. Fukushima J Med Sci 2014;60:57-67.

14. Ohira T, Hosoya M, Yasumura S, et al. Effect of evacuation on body weight after the Great East Japan Earthquake. Am J Prev Med 2016:50:553-60.
15. Satoh $\mathrm{H}$, Ohira $\mathrm{T}$, Hosoya $\mathrm{M}$, et al. Evacuation after the Fukushima Daiichi nuclear power plant accident is a cause of diabetes: results from the Fukushima health management survey. $J$ Diabetes Res 2015;2015:627390.

16. Antonovsky A. The structure and properties of the sense of coherence scale. Soc Sci Med 1993;36:725-33.

17. Konishi E, Nagai T, Kobayashi M, et al. Post-Fukushima radiation education for public health nursing students: a case study. Int Nurs Rev 2016;63:292-9.

18. Ohtsuru A, Tanigawa K, Kumagai A, et al. Nuclear disasters and health: lessons learnt, challenges, and proposals. Lancet 2015;386:489-97.

19. Goto A, Lai AY, Rudd RE. Health literacy training for public health nurses in Fukushima: a multi-site program evaluation. Japan Med Assoc J 2015;58:69-77.

20. Wainwright NW, Surtees PG, Welch AA, et al. Healthy lifestyle choices: could sense of coherence aid health promotion? J Epidemiol Community Health 2007;61:871-6.

21. Eriksson M, Lindström B. Antonovsky's sense of coherence scale and the relation with health: a systematic review. J Epidemiol Community Health 2006;60:376-81.

22. Tanaka I, Higa H, Yamada K. Comparison of clinical nursing competence based on attributes of nurses, and relationship between number of working years, sense of coherence, and spirituality. Toyama Univ J Nurs 2012;12:81-92. (in Japanese).

23. Kawabata M. Related factors to the spirituality and sense of coherence (SOC) of nurses involved in the nursing of terminal stage cancer patients. Stud Nurs Rehabil 2011;1:41-9. (in Japanese).

24. Kimura M, Yamazaki Y. Mental health and positive change among Japanese mothers of children with intellectual disabilities: roles of sense of coherence and social capital. Res Dev Disabil 2016;59:43-54. 